\title{
The Effects of the Cervical Deep Muscle Flexion Exercises on Pain and Cervical Function in Patients with Chronic Cervical Pain
}

\author{
Won-Ho Choi \\ Dept. of Physical Therapy, Gachon University
}

\begin{abstract}
Purpose This study was conducted to verify that the cervical deep muscle flexion exercises (CDFE) benefit on stability in the neck so that the patients would have less pain and better cervical function. Methods The subjects in this study were assigned into an experimental group (EG) of 16 subjects and a control group (CG) of 16 subjects. The CDFE and stretching exercise (SE) were applied to the EG and CG, respectively. And, visual assessment scale (VAS) for pain and neck disability index (NDI) for cervical function were used to assess the subjects before and after the intervention. The subjects performed the exercises 3 times a week for 4 weeks. Results There was a significant difference in variations of cervical pain in between the EG and CG from $25.16 \pm 13.29$ to $6.38 \pm 8.14 \mathrm{~mm}$. There was a significant difference in variations of neck functional disability in between the EG and CG from $4.94 \pm 2.17$ to $0.25 \pm 1.73$ point. Conclusion The subjects performed the CDFE for 4 weeks were able to correct the spine alignment and strengthen the muscles around the cervical region, which was able to reduce stress on the neck so that cervical pain was reduced and the neck functional ability was increased.
\end{abstract}

Key words Chronic neck pain, Deep muscle flexion exercises, Neck functional disability, Stretching exercise, Visual pain scale

Corresponding author whchoi@gachon.ac.kr

$\begin{array}{lll}\text { Received date } & 10 \text { January } 2019 \\ \text { Revised date } & 01 \text { February } 2019 \\ \text { Accepted date } & 11 \text { February } 2019\end{array}$

\section{Introduction}

Cervical lesion which is a high mobidity and costing disease is getting increased by overuse of muscles around the neck in repetitive and continuous tasks in a work place nowadays. ${ }^{1)}$ Using a fixed gadget for a while in sitting positon is prone to explore to static loading. And a desk and chair with unfitted physical condition as well as a lack of exercise can be possible causes ${ }^{2)}$ to develop health problems in the neck because of a poor posture. ${ }^{3)}$ If the neck pain goes consistently more than 3 months, it is regarded as a chronic cervical pain ${ }^{4}$, and head forward protraction is the main cause of the pain in the neck ${ }^{5)}$ causing increased lordosis in cervical region and shortness in muscles around the suboccipital region. ${ }^{6}$ ' Therefore, this posture induces weakness of the deep flexor muscles in cervical region and causes pain and in- stability in the neck. ${ }^{7}$ The previous study showed that the exercises strengthening the deep flexor muscles in cervical region alleviated pain and got the subjects to have a right posture back. The exercises focused on improving functional problems of muscles around the cervical region. 5) The previous study introduced the exercise program for stability in the neck. To place the cervical region in neutral position helped the cervical region be stabilized and minimize activation of the superficial muscles such as sternocleidomastoid and anterior scalene and facilitate more the deep flexor muscles such as longus coli and longus capitis. Therefore, the cervical deep muscle flexion exercises (CDFE) benefit on chronic neck pain and stability in the neck so that the patients with forward head protraction would have less pain and better cervical function. 


\section{Materials and Methods}

Thirty-two subjects with chronic neck pain because of forward head protraction participated in this study and understood the purpose of the study and submitted the informed consent. This study was conducted from November $1^{\text {st }}$ to $31^{\text {st }}, 2017$.

The including criteria were as follows: 1) below $49^{\circ}$ of the Craniovertebral angle.9) 2) having constant or intermittent neck pain within last 3 months. The excluding criteria were as follows: 1) neurologic or vascular problems. 2) orthopedic problems in the neck or shoulder region. 3) a surgery in the spine before.

The subjects in this study were assigned into an experimental group (EG) of 16 subjects and a control group (CG) of 16 subjects by table of random number of Microsoft Excel 2010 Program.

The CDFE and stretching exercise (SE) were applied to the EG and CG, respectively. And, visual assessment scale (VAS) for neck pain and neck disability index (NDI) for cervical function were used to assess the subjects before and after the intervention. The subjects performed the exercises 3 times a week for 4 weeks. The assessments were performed 3 times and yielded the mean value of them.

The intervention consists of the CDFE and SE. 1. The cervical deep muscle flexion exercises

(1) General isometric exercise

Two general isometric exercises were performed separately according to a week. In first $1^{\text {st }}$ and $2^{\text {nd }}$ weeks, the subjects performed the conventional cervical isometric exercise 1 . The subjects stand with the head and thoracic region leaning on a wall and the chin and shoulders in neutral. And then, the subjects perform isometric exercises as flexing independently their cervical region down until the lower cervical regions do not flex which was controlled by feedback of the base of the support in the ground. In $3^{\text {rd }}$ and $4^{\text {th }}$ weeks, the subjects performed the conventional cervical isometric exercise 2. The subjects stand facing toward the wall and put the forearm on the wall so that the scapulars should be placed in neutral. And then, they flex only cervical regions down as they maintain their heads over and behind the shoulders. The exercises were performed 10 repetitions per 1 session, a total of 3 sessions, maintaining each repetition for 10 seconds and took 3-5 seconds rest between the repetitions and a 2 -minute rest between the sessions. ${ }^{10)}$

\section{(2) Exercises with pressure biofeedback unit}

The subjects in hook-lying position take a look at the pressure scale as pressing down the air bag in the suboccipital portion by tucking the chin in $(22 \mathrm{mmHg}$ in $1^{\text {st }}$ week, $24 \mathrm{mmHg}$ in $2^{\text {nd }}$ week, $26 \mathrm{mmHg}$ in $3 \mathrm{r}^{\mathrm{d}}$ week, 28 $\mathrm{mmHg}$ in $4^{\text {th }}$ week). The exercises were performed 10 repetitions per 1 session, a total of 3 sessions, maintaining the pressure on the target level for 10 seconds and given a 2-minute rest between the sessions. ${ }^{11)}$

\section{Self-stretching exercises}

$\mathrm{SE}^{12)}$ were performed for pectoralis minor and major, levator scapular and upper trapezious which were shortened due to upper cross syndrome.

\section{(1) Pectoralis major and minor stretching}

A subject sits on a chair tall and tight with the chin tucked in and grabs an elastic band that he/she can pull the band down behind the head after putting his/her arms up over the head. The subject maintains the stretched position for 45 seconds which is 1 session and repeats 3 times for 1 session.

\section{(2) Levator scapulae stretching}

A subject sits on a chair tall and tight with the chin tucked in and holds the chair with the hand in the opposite side to the levator scapular stretched. The subject holds the back of the head with the other hand and pulls the head down with head rotated to the same side of the hand holding the head. The subject maintains the stretched position for 45 seconds which is 1 session and repeats 3 times for 1 session in the left and right side.

\section{(3) Upper trapezius stretching}

A subject sits on a chair tall and tight with the chin 
Table 1. General characteristics of the subjects $(\mathrm{N}=32)$

\begin{tabular}{|c|c|c|c|c|}
\hline & & $E G(n=16)$ & \multirow{2}{*}{$C G(n=16)$} & \multirow{2}{*}{$p$} \\
\hline & & {$[n(\%) / M \pm S D]$} & & \\
\hline \multirow{2}{*}{ Gender } & Male & $8(50 \%)$ & $11(68.8 \%)$ & \multirow{2}{*}{$0.280^{\mathrm{a}}$} \\
\hline & Female & $8(50 \%)$ & $5(31.2 \%)$ & \\
\hline \multicolumn{2}{|r|}{ Age(years) } & $30.1 \pm 2.7$ & $31.0 \pm 5.2$ & $0.525^{\mathrm{b}}$ \\
\hline \multicolumn{2}{|r|}{ Height $(\mathrm{cm})$} & $164.4 \pm 7.7$ & $163.8 \pm 8.2$ & $0.843^{\mathrm{b}}$ \\
\hline \multicolumn{2}{|r|}{ Weight(kg) } & $61.8 \pm 10.5$ & $63.4 \pm 9.9$ & $0.656^{\mathrm{b}}$ \\
\hline
\end{tabular}

${ }^{\mathrm{a}}$, Chi-squared test; ${ }^{\mathrm{b}}$, Independent-t test; EG, Experimental group; CG, Control group

Table 2. Variations of cervical pain $(\mathrm{N}=32)$

\begin{tabular}{cccccc}
\hline & & EG $(n=16)$ & CG $(n=16)$ & $t$ & $p$ \\
\hline VAS & Pre-test & $51.38 \pm 22.93$ & $46.06 \pm 20.74$ & -2.252 & $0.033 \mathrm{~L}$ \\
$(\mathrm{~mm})$ & Post-test & $26.25 \pm 14.08$ & $39.69 \pm 19.28$ & \\
& $t$ & 7.562 & $0.007^{* *}$ & \\
\hline
\end{tabular}

$\mathrm{M} \pm \mathrm{SD} ;{ }^{*}, p<.05$ Significant differences pre and post tests; ${ }^{* *}, p<.001$ Significant differences pre and post tests; ${ }^{\dagger}, p<.05$ Significant differences between the two groups; VAS, Visual analog scale; EG, Experimental group; CG, Control group

tucked in and holds the chair with the hand in the opposite side to the upper trapezius stretched. The subject holds the side of the head with the other hand and pulls the head down sideway to the same side of the hand holding the head. The subject maintains the stretched position for 45 seconds which is 1 session and repeats 3 times for 1 session in the left and right side.

Visual analog scale(VAS) was used to assess pain in the neck. ${ }^{13)}$ And, neck disability index (NDI) was used to assess functional disability in the neck. NDI consists of 10 questions (pain scale, activity of the daily living, lifting, reading, headache, attention, work, driving, sleeping and leisure) and was developed to assess the level of functional disability. Each item scales from 1 to 5 points and if the total points are from 0 to 4 points, it means "No disability", 5 to 14 points means "mild disability", 15 to 24 points means "moderate disability", 25 to 34 points means "severe disability" and above 25 points means "complete disability". ${ }^{14)}$

\section{Results}

\section{General characteristics of the subjects}

There were 16 subjects in the EG ( 8 males and 8 females, mean age of $30.1 \pm 2.7$ years old, mean height of $164.4 \pm 7.7 \mathrm{~cm}$, mean weight of $61.8 \pm 10.5 \mathrm{~kg})$ and the CG (11 males and 5 females, mean age of $31.0 \pm$ 5.2 years old, mean height of $163.8 \pm 8.2 \mathrm{~cm}$, mean weight of $63.4 \pm 9.9 \mathrm{~kg}$ ) each. There was not a significant difference in homogeneity between the groups. Table 1 shows the general characteristics of the subjects in this study.

\section{Variations of cervical pain}

There were significant differences from $51.38 \pm 22.93$ $\mathrm{mm}$ to $26.25 \pm 14.08 \mathrm{~mm}$ and from $46.06 \pm 20.74 \mathrm{~mm}$ to $39.69 \pm 19.28 \mathrm{~mm}$ in the EG and CG, respectively. There was a significant difference in between the EG and CG from $25.16 \pm 13.29 \mathrm{~mm}$ to $6.38 \pm 8.14 \mathrm{~mm}$. (Table 2)

\section{Variations of neck functional disability}

There was a significant difference from $18.25 \pm 3.79$ to $13.31 \pm 2.70$ points in the EG. There was a significant difference in between the EG and CG from 
Table 3. Variations of neck functional disability ( $N=32)$

\begin{tabular}{rccccc} 
& & EG $(\mathrm{n}=16)$ & CG $(\mathrm{n}=16)$ & $t$ & \\
& Pre-test & $18.25 \pm 3.79$ & $16.25 \pm 3.92$ & -2.375 & $.025+$ \\
NDI & Post-test & $13.31 \pm 2.70$ & $16.00 \pm 3.63$ & .577 \\
(score) & $t$ & 9.082 & .572 & \\
& $p$ & $0.000^{* *}$ & & \\
\hline
\end{tabular}

$\mathrm{M} \pm \mathrm{SD} ;{ }^{* *}, p<.001$ : Significant differences pre and post tests; ${ }^{\dagger}, p<.05$ Significant differences between the two groups; NDI, Neck Disability Index

$4.94 \pm 2.17$ to $0.25 \pm 1.73$ points. (Table 3 )

\section{Discussion}

The subjects with chronic cervical pain in this study has conducted the CDFE and SE for 4 weeks and analyzed variations of cervical pain and NDI. Pain in the both groups was reduced after 4-week exercises significantly. In previous study, deep muscle flexion exercises influenced pain control and proper spine alignment ${ }^{15)}$, and the similar study showed that the group performed deep muscle exercises benefited in pain and function significantly than the control group. ${ }^{16)}$ This study showed that the CDFE for neck reduced pain. This is because the CDFE can influence on maintaining a neutral position of the neck from forward protracted neck by increased muscle strength and stability of the deep muscle flexors which reduced superficial tension in the neck. Moreover, the CG showed a significant difference in cervical pain. This is because stretching exercises could elongate the muscles shortened in cervical and the thoracic regions due to upper cross syndrome, which got the shortened muscles to go back to normal length of the muscles so that the range of motion in the cervical and thoracic regions increased and the alignment of these came back to normal range of the alignment. The previous study applied stretching to the subjects proved that the exercises influenced pain control. $^{17)}$

In this study, the EG showed a significant difference in NDI. The previous study showed that deep flexors exercises applying to the patients with chronic cervical pain for 6 weeks influenced neck functional disability and pain. ${ }^{18)}$ And another study applied deep flexor muscle exercises to the patients with a particular occupation for 4 weeks proved decreased pain and neck functional disability. ${ }^{19)}$ In addition, the previous study showed that the muscle strength and endurance exercises for 12 months influenced chronic cervical pain and neck functional disability. ${ }^{20)}$ These studies support the results of this study that the CDFE more influenced positively on cervical pain and NDI than other regular exercises. As a whole, the subjects performed the CDFE for 4 weeks were able to correct the spine alignment and strengthen the muscles around the cervical region, which was able to reduce stress on the neck so that cervical pain was reduced and the neck functional ability was increased.

\section{References}

1. Tepper M, Vollenbroek-Hutten MM, Hermens HJ, et al. The effect of an ergonomic computer device on muscle activity of the upper trapezius muscle during typing. Appl Ergon. 2003;34(2):125-30.

2. Jang C. The Effects of Breathing Exercise on Forward Head Posture. Daegu University. 2010.

3. Nejati P, Lotfian S, Moezy A, et al. The study of correlation between forward head posture and neck pain in Iranian office workers. Int J Occup Med Environ Health. 2015;28(2):295-303.

4. Wheeler AH. Diagnosis and management of low back pain and sciatica. Am fam physician. 1995;52(5):1333-41.

5. Szeto GP, Straker L, Raine S. A field comparison of neck and shoulder postures in symptomatic and asymptomatic office workers. Appl Ergo. 2002;33(1):75-84.

6. Harrison DE, Harrison DD, Betz JJ, et al. Increasing the cervical lordosis with chiropractic biophysics seated combined extension-compression and transverse load cervical traction with cervical manipulation: 
nonrandomized clinical control trial. J Manipulative physiol ther. 2003;26(3):139-51.

7. Fernandez-de-las-Penas C, Perez-de-Heredia M, Molero-Sanchez A, et al. Performance of the craniocervical flexion test, forward head posture, and headache clinical parameters in patients with chronic tension-type headache: a pilot study. J Orthop Sports Phys Ther. 2007;37(2):33-9.

8. Cagnie B, Dirks R, Schouten M, et al. Functional reorganization of cervical flexor activity because of induced muscle pain evaluated by muscle functional magnetic resonance imaging. Man Ther. 2011;16(5):470-5.

9. Nemmers TM, Miller JW, Hartman MD. Variability of the forward head posture in healthy community-dwelling older women. J Geriatr Phys Ther. 2009;32(1):10-4.

10. Comerford MJ, Mottram SL. Diagnosis of uncontrolled movement, subgroup classification and motor control retraining of the neck. Kinetic Control, UK. 2011.

11. Jesus FM, Ferreira PH, Ferreira ML. Ultrasonographic measurement of neck muscle recruitment: a preliminary investigation. J Man Manip Ther. 2008;16(2):89-92.

12. Evjenth O, Hamberg J. Auto stretching : the complete manual of specific stretching. sweden Alfta rehab forlag. 2004.

13. Wang WT, Olson SL, Campbell AH, et al. Effectiveness of physical therapy for patients with neck pain: an individualized approach using a clinical decision-making algorithm. Am J Phys Med Rehabil. 2003;82(3):203-18.
14. Lee EW, Sin WS, Jung KS, et al. Reliability and Validity of the Neck Disability Index in Neck Pain Patients. Physical Therapy Korea. 2007;14(3):97-103.

15. Park GN, Won JH, Lee WH, et al. Effects of Contraction of Abdominal Muscles on Electromyographic Activities of Superficial Cervical Flexors, Rib Cage Elevation and Angle of Craniocervical Flexion During Deep Cervical Flexion Exercise. Physical Therapy Korea. 2009;16(3).

16. Chiu TT, Lam TH, Hedley AJ. A randomized controlled trial on the efficacy of exercise for patients with chronic neck pain. Spine. 2005;30(1):E1-7.

17. Lee HS, Ryu JH. The Effects of Stretching and Isometric Exercise for Chronic Neck Pain Patient in Strength and Pain. Korean Soceity of Physical Medicine. 2012;7(3):329-37

18. Chiu TT, Ku WY, Lee MH, et al. A study on the prevalence and risk factors forneck pain among university academic staff in Hong Kong. J Occup Rehabil. 2002;12(2):77-91.

19. Falla DL, Jull GA, Hodges PW. Patients with neck pain demonstrate reduced electromyographic activity of the deep cervical flexor muscles during performance of the craniocervical flexion test. Spine. 2004;29(19):2108-14.

20. Ylinen J, Takala EP, Nykanen M, et al. Active neck muscle training in the treatment of chronic neck pain in women: a randomized controlled trial. Jama. 2003;289(19):2509-16. 
